\title{
The Language of Description and Theorizing in Reflective Discourse
}

\author{
Vivian Darroch and Ronald J. Silvers
}

The Ontario Institute for Studies in Education

It appears paradoxical that while there may be considerable agreement amongst phenomenologists discussing what phenomenology is or should be, those same phenomenologists sharply differ when discussing phenomenology in the doing of it. This difference between writing about phenomenology and phenomenological writing constitutes the focus of our response to Ton Beekman's review (Phenomenology + Pedagogy, Vol. 1, No. 2) of our book, Interpretive Human Studies. For in his review, Beekman makes frequent reference to his support for the position upon which our work is based while criticizing our language and writing in the presentation and demonstration of that position.

In our comments here we do not intend to account for such differences by locating Beekman's principles and assumptions in contrast to our own. It would be more fruitful and analytically more interesting to examine the features of phenomenological discourse which were designated as problematic for a reader's understanding. We choose to focus on phenomenological discourse since it is there that phenomenology is manifested. And more important, it is from phenomenological discourse that we may reflectively come to know what phenomenology is as a practice in the human sciences. Thus, we look to how what is written, in the doing of research and in the conveying of research, to allow us to discover that practice.

Let us return to those sections of Beekman's review in which he describes his difficulties with our language and style of writing. In doing so, we will try to address the excerpts he quotes and see how, within an interpretive analysis, they may be understood.

Beekman designates the following as an example of obtuse writing:

For in naming our research interpretive inquiry we pursue the understanding of what is personal and what is social by an uncovering and recovering of the other's understanding of experience. But interpretive inquiry which is existential also begins with the premise that we cannot share the same experience. We cannot enter the subjectivity of others, nor can they know our consciousness in its interiority. Thus the mental construction of an experiment is ruled out. What can be shared are the moments of experiencing. But the sharing of these moments is not in the experience but in our existence. (Beekman, p. 230) 
We note that the last two sentences, following each other as they do, may "appear" to shift an idea or even to contradict each other. What is set up in the relationship of the two sentences are two ideas which, interpretively speaking, create for the reader divergent paths of understanding. The reader may ask, Is that which is shared in experience or not in experience (but, instead, in existence)? The movement of discourse in Interpretive Human Studies cannot respond with a direct and decisive clarity to such a question because its primary purpose is to present the authors' reflective process and, in pursuit of that purpose, requests understanding from the reader. Our discussion here examines what is necessary for this understanding. Thus, a seeming contradiction such as is found in the quote above is an occasion for interpretive analysis by ourselves although this time not as authors but as readers.

If we pay attention to "ing" as a signal of enactment or motion, then in the first of the last two sentences the emphasis is upon "experiencing." "Shared" is yet only a potentiality. In the second sentence the activity of "sharing" carries the moments referred to in the first sentence beyond themselves into existence. Further, the second sentence can only be expressed as a consequence of reflection of the first.

So why, a reader may ask, do the authors not finally link the two sentences or perhaps rewrite them in a synthesis of the two ideas, especially since this is an introduction to phenomenology? Here we respond as authors of the quoted passage and say that the writing attempts to preserve the motion of its reflective thought rather than let it come to rest as a declaration. Again shifting to the position of the reader, we note that in the sentence immediately above, it is "writing" which is said to preserve the motion of its reflective thought; it is not that we as authors are attempting to preserve this motion. Pursuing this point further in reflection, writing appears to have a life of its own; it does not seem to be a product of the authors' purpose or intentionality.

If an interpretive phenomenology is granted to be always incomplete-that is, its discourse always requiring a presence of a hearer or reader to form its meaning - then its writing also must preserve openness or incompleteness. In this regard a reflective discourse does not struggle for ultimate "clarity"; it does not wish to arrive at a reductive point for agreement. Instead, it seeks to elicit a dialogue between author and reader and, further, to initiate reflective thought in the reader.

The objective of a discourse which seeks dialogue is the hermeneutic effort to arrive at an understanding of our continual interpretive process. We discover through such writing that this effort is directed 
not to arrive at process in order to present it as substance-to objectify the process-but to continually show our way within the process. That would mean that we would show the turns, changes, and contradictions in our reflective thought.

With these above comments in mind we turn now to what the reader may feel that he or she needs to know. Beekman writes about Darroch's description: "the text goes on and on and the vision seems to be about a 'tea party in the wheat field' although at the same time there never was a wheat field" (p. 230). The point here, as an interpretation within a reflective discourse, is not whether there was or wasn't a wheat field, but for writer and reader to explore what it is to say or write that there was ... and then later that there never was a "wheat field."

Similarly, an open text cannot be knitted neatly together. It requires spaces to which the writer herself or himself refers and returns in reflection-but not in resolution. Hence, the three-times naming of a place of writing, as Beekman notes (p. 231) in a second case of Darroch's, is relevant for an author. The question is: How may it be relevant for the reader? We strongly underline the term may since in the egalitarian structure of hermeneutic discourse there is neither authority of origin (writer) nor authority of destination (reader). How it may be relevant for the reader is for the reader to recognize that what is being studied in what we propose is not the experience of the other, but our experience of the other.

Is the reflective discourse we describe here far from the lifeworld, as Beekman implies? We believe not, but in order to believe not we must distinguish between a language which speaks about the lifeworld and the language we ordinarily find within our lifeworld. If we are attempting to introduce self-reflection about ordinary life, then we cannot use the language of what has been referred to by others as the "natural attitude," (Schutz, 1971) the taken-forgranted. We must enter into a form of thought, perhaps a form of fuller consciousness, in which the language used to reflect upon the taken-for-granted takes its shape.

Let us look at another quotation from Interpretive Human Studies and the response in Beekman's review. The excerpt is from Terrance Trussler's paper, "Mapping A Region of Social Experience":

I could see the edge of the broken clouds across the sun opening up a clear sky. I began to wade slowly back toward the shore watching the ripple of water form around my ankles; my thoughts ran out to a blank tension. Then I turned on my step and glanced at Rob, feeling a grin on my face, seeing it returned on his. And we started running out across the shallows of the beach, screaming "ya h h h h h h hhhhh."(Beekman, p. 231) 
Beekman's response to this passage is: "After these 12 ' $h$ 's' I myself felt like screaming!"

Even as a biographical description of experience, this form of writing by Trussler is a language of existing. But further, the $12 \mathrm{~h}$ 's may be interpreted as a signal of understanding before it is named. The 12 h's may carry moments of experience into existence. Again, the significance is not what the "point" of the description is but rather what the process is within the description.

Similarly, in his review of Silvers' research paper, Beekman asks what the value is of the three voices of reflective discourse. Beekman finds Silvers' paper arduous, obvious, and his conclusions similar to those of others. However, the value of the three voices was not to arrive at a conclusion-again, knowledge as substance-but to account for the character of an experience (in this case, the absence of a communicative relationship between researcher and child-a phenomenological researcher engaged in study of videotapes of Piagetian interviews). The analysis did not intend to create (as did Donaldson's analysis) a critique of Piagetian theory.

Finally, Beekman addresses the question of relationship between the researcher and child as: "Silvers looked at tapes of children he did not know." Here we wish to note that Interpretive Human Studies tries to move beyond the quality of relationship with children or others which depends on empathic understanding (whether one is with "other" or not). It is not "humanistic" values and attitudes which are central; they alone do not ensure the presence of a researcher's self in work with others. Rather, what is required is an interpretive, analytic movement which lays bare the ways in which we as researchers relate to and are alienated from those we seek to understand and communicate with. Thus it is not necessarily relevant to personally know those with whom we seek to understand and communicate.

Within phenomenology, just as within positivism, we find the very processes of objectification that we so strongly reject. (That was the nonobvious insight in Silvers' paper.) We think that it is important to understand that the condemning of objectification in principle does not ensure its absence from our work because the condemning of objectification in principle does not remove the source of objectification from our consciousness. Entering into a communicative relationship depends upon attempting an understanding of and responsibility for that which prohibits a communicative relationship. Such has been the attempt in this paper as we address the concerns expressed by Ton Beekman.

\section{References}

Schutz, A. (1971). Collected Papers I, Part III. The Hague: Martinus Nijhoff. 